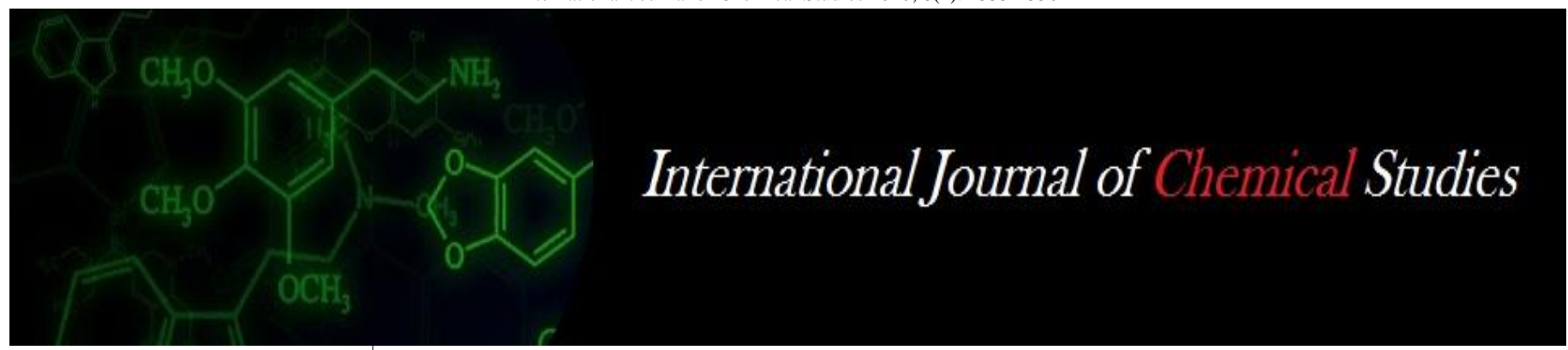

P-ISSN: 2349-8528

E-ISSN: 2321-4902

www.chemijournal.com

IJCS 2020; 8(2): 1553-1556

(C) 2020 IJCS

Received: 10-01-2020

Accepted: 12-02-2020

\section{Kaustubh Das}

Division of Horticulture, ICAR

Research Complex for NEH

Region, Tripura Centre,

Lembucherra, Tripura, India
Corresponding Author: Kaustubh Das

Division of Horticulture, ICAR

Research Complex for NEH

Region, Tripura Centre,

Lembucherra, Tripura, India

\title{
Role of organic and environment friendly post harvest management of organically grown horticultural produces
}

\section{Kaustubh Das}

\section{DOI: https://doi.org/10.22271/chemi.2020.v8.i2x.8983}

\begin{abstract}
Horticultural crops play a unique role in India's economy by improving the income of the rural people. Cultivation of these crops is labour intensive and as such they generate lot of employment opportunities for the rural population. Fruits and vegetables are fastest growing sectors within horticulture. India produces around 111.77 million MTs of vegetables and 57.73 million MTs of fruits, which respectively accounts for nearly $11.90 \%$ and $10.90 \%$ of country's share in the world production of vegetables and fruits. India ranks second in world in both categories. Since, fruits and vegetables are highly perishable, efficient Post Harvest Management has become an absolute necessity. It is also important for effective exploitation of the export potential of fruits and vegetables. Joint effort of R\&D institutions, farmers, government agencies and traders has resulted in India emerging as a major producer of fruits and vegetables in the world. But the magnitude of loss in food grains is to the tune of $10 \%$ whereas for fruits and vegetables losses are estimated at 35-40\% due to improper Post Harvest Management (PHM) (XI Planning Commission). It amounts to a loss estimated at Rs 40,000 crores per year. In India post harvest losses of fruits and vegetables every year equivalent to the annual consumption of the United Kingdom. So there is need to have a strong post harvest infrastructure for post harvest management of these perishables. Organically grown horticultural products are mainly purchased for their safety and absence of synthetic pesticide residues and others harmful chemicals. So it's must be more important to management of organic produces after harvesting in such a way, that must be free from human hazards. The aims of organic post harvest management of organically grown fruits and vegetables for prevent senescence and losses of fruits and vegetables after harvest as well as increasing the shelf life and maintaining the quality of organic horticultural produces for better health.
\end{abstract}

Keywords: Eco-friendly post harvest management, practices, organic horticulture

\section{Introduction}

Fruit \& Vegetable varieties

Quality for most crops cannot be improved during storage, only maintained and therefore any consideration of storage must take into account the importance of variety and preharvest factors. The absence of postharvest chemical treatments for organic growers, make it even more important that varieties are selected with these factors in mind. Variety selection should also include resistance to postharvest diseases and physiological disorders.

\section{Maturity at Harvest}

Decision associated with harvest maturity and the way the commodity is handled and stored can greatly affect storage life of even the most long-lived fruit or vegetable. For fully developed fruits, two competing factors often exist. On one hand, characteristics of the products such as sweetness and flavor that are desired by the consumer increase as they mature and ripen. At the same time, the storability of the products continues to decrease. The outcome of these competing factors is that fruit destined for storage should be harvested earlier than one that is suitable for immediate consumption.

\section{Harvest Handling}

The inherent quality of produce cannot be improved after harvest, only maintained for the expected window of time (shelf life) characteristics of the commodity. As a general approach for organic growers, the following practices can help you maintain quality. 
First, harvesting the produces during the coolest time of day to maintain low product respiration. Second, avoid unnecessary wounding, bruising, crushing or damage from humans, equipment or harvest containers. Third, shade the harvested product in the field to keep it cool. By covering harvest bins with a reflective pad, you greatly reduce heat gain from the sun, water loss and premature senescence. Fourth, move the harvested product into a cold storage facility or postharvest cooling treatment as soon as possible. Fifth, do not compromise high quality product by mingling it with damage, decayed or decay-prone product in a bulk or packed unit. Sixth, only use cleaned and as necessary, sanitized packing or transport containers.

\section{Handling considerations}

1. Containers should be clean and should be used only for organically grown produce to avoid any possibility of chemical contamination.

2. High pressure wash, rinse and sanitize all containers prior to use.

3. Clean containers should be covered to avoid contamination after cleaning.

4. Containers should not have rough surfaces that can damage produce.

5. Damaged or spoiled produce should be left in the field to reduce contamination by decay organisms.

\section{Ethylene}

A further factor that must be considered in storage of fruits and vegetables in ethylene, a naturally occurring plant growth regulator that affects many aspects of growth and development of plants. Ethylene is naturally occurring in plant tissues and is a critical part of normal ripening for many fruits. However, increased ethylene production can occur as a result of disease and decay, exposure to chilling temperatures and wounding. External ethylene will stimulate loss of quality, reduce shelf life, increase disease and induce specific symptoms of ethylene injury, such as the following:

- Russet spotting of lettuce

- Yellowing or loss of green color incase of vegetables like cucumber, broccoli, kale, spinach

- Increased toughness in turnips and asparagus spears.

- Bitterness in carrots and parsnips

- Yellowing and abscission (dropping) of leaves in Brassicas.

- Softening, pitting and development of off-flavor in peppers, summer squash and watermelons.

- Browning and discoloration in eggplant pulp and seed

- Discoloration and off-flavor in sweet potatoes.

- Increased ripening and softening of mature green tomatoes.

Countermeasures against ethylene:

\section{Avoidance- Removing sources of ethylene}

Avoidance of exposure to ethylene begins with careful harvesting, grading and packing to minimize damage to the commodities. In the case of climatic products it is difficult to reduce the interval levels of ethylene once autocatalytic production has started. Products should be cooled rapidly to their lowest safe temperature to reduce naturally occurring ethylene production and to decrease sensitivity to ethylene.

\section{Ventilation}

Ethylene concentrations in the storage environment can be reduced by ventilation with clean fresh air. However, the fresh air has to be cooled and increasing ventilation is therefore energy intensive.

\section{Ethylene absorbers, oxidation and catalysis}

Ethylene in storage rooms can be lowered by absorption or oxidation. Adsorbers such as activated carbon and zeolites (microporus aluminosilicate minerals) have been available for many years. Ozone will also oxidize ethylene, and its use in slowing down ripening as well as a disinfectant that lowers mold and bacterial contaminations, has been documented.

\section{Modified Atmosphere (MA) and Controlled Atmosphere (CA) storage}

MA storage refers to a change in the atmosphere around the product. MA can be developed passively by product respiration or by active means. CA storage is a subset of MA storage, but as the name suggests, the atmosphere around the product is controlled.

\section{Storage Temperature}

The most fundamental postharvest tool available to the fruit and vegetable grower is temperature control. It is critical to decrease the temperature of fruit and vegetables as quickly as possible after harvest to slow down their metabolism, unless curing is part of post harvest management.

Methods of cooling are utilized for organically grown vegetables and fruits

Room cooling- An insulated room or mobile container equipped with refrigenaration units. Room cooling is slower than other methods. Depending on the commodity, packing unit and stacking arrangement the product may cool too slowly to prevent water loss, premature ripening or decay.

Forced air cooling- Fans used in conjunction with a cooling room to pull cool air though packages of produce. Although the cooling rate depends on the air temperature and the rate of airflow, this method is usually 75 to $90 \%$ faster than simple room cooling.

Hydro cooling- Showering produce with chilled water to remove heat and possibly to clean produce at the same time. The use of a disinfectant in the water is essential.

Vacuum cooling- uses a vacuum chamber to cause the water within the plant to evaporate, removing heat from the tissues. This system works well for leafy crops that have a high surface to volume ratio, such as lettuce, spinach and celery. The operator may spray onto the produce before placing it into the vacuumed chamber. The high cost of the vacuum chamber system restricts its use to larger operations. 
Table 1: Comparison among cooling methods

\begin{tabular}{|c|c|c|c|c|c|}
\hline & \multicolumn{5}{|c|}{ Cooling Method } \\
\hline Variable & Ice & Hydro & Vacuum & Forced-air & Room \\
\hline Cooling times (h) & $0.1-0.3$ & $0.1-1.0$ & $0.3-2.0$ & $1.0-10.0$ & $20-100$ \\
\hline Water contact with the product & Yes & Yes & No & No & No \\
\hline Product moisture loss (\%) & $0-0.5$ & $0-0.5$ & $2.0-4.0$ & $0.1-2.0$ & $0.1-2.0$ \\
\hline Capital cost & High & Low & Medium & Low & Low \\
\hline Energy efficiency & Low & High & High & Low & Low \\
\hline
\end{tabular}

Source: Kader \& Rolle (2003)

\section{Sanitation}

Water disinfection should be integrated into every face of postharvest handling. Escherichia coli, Salmonella, Shigella, Listeria, Cryptosporidium, Hepatitis and Cyclospora are the among the diseases and disease causing organisms that have been associated with fresh fruits and vegetables.

\section{GAP protocols for sanitation of organically grown} horticultural produces:

- Ensure that contaminated water or livestock waste cannot entre the packinghouse via run-off of drift.

- Wash, rinse and sanitize packing areas and floors at the end of each day.

- Exclude birds and animals both domesticated and wild (i.e. rodents).

- Field clothes, especially shoes and boots should be kept clean and sanitary, using organically allowable disinfectants, frequent water changes and daily attention to sanitizing all food contact surfaces at the end of each working day.

- Use of disposable gloves should be encouraged for workers on packing lines.

\section{Approved Chemicals for use in organic postharvest} system

- Chlorine: Chlorine is a very common disinfectant that can be added to transport flumes or to produce cooling or wash water. Liquid sodium hypochlorite is typically used, with the $\mathrm{pH}$ of the water maintained between 6.5 and 7.5 to optimize effectiveness.

- Ozone: Ozone is becoming an increasingly popular alternative to chlorine for water disinfection. Ozone is considered GRAS (Generally Regarded As Safe) for produce and equipment disinfection. Ozone, through its action as oxidizer, rapidly attacks bacterial cell walls and thick-walled spores of plant pathogens.

- Acetic acid: Allowed as a cleanser or sanitizer. Vinegar used as an ingredient must be form an organic source.

- Alcohol, Ethyl: Allowed as a disinfectant. To be used as an ingredient must be form an organic source.

- Bleach: Calcium hypochlorite, sodium hypocholorite and chlorine dioxide are allowed as a sanitizer for water and food contact surfaces.

- Detergents: Allowed as equipment cleaners. Also includes surfactants and wetting agents.

- Hydrogen peroxide: Allowed as a water and surface disinfectant.

- Carbon dioxide: Permitted for postharvest use in modified and controlled atmosphere storage and packaging. For crops that tolerate treatment with elevated $\mathrm{Co} 2(\geq 15 \%)$, suppression of decay and control of insect pests can be achieved.

\section{Packaging}

Packaging materials, storage containers or bins must be free of synthetic fungicides, chemical preservatives and fumigants. They also must be free of any residue from cleaning and sanitizing. Containers that are to be reused must be of the type that can be thoroughly cleaned prior to use.

\section{Protection}

Packages must provide protection for the product against environment factors such as dust and water, as well as impact and compression bruising and friction injuries that can occur during handling and transport. Cartons must have stacking strength and durability to prevent collapse or crushing while they are on pallets, especially under high relative humidity conditions.

\section{Convenience}

Products are packaged in sizes that are convenient for the consumer, but may be larger for transport because of economic scale. The product may be removed from the container and placed in display as single units or repackaged.

\section{Communication}

In addition to advertising the type and source of the produce, information is provided about gross and net package weight, unit size of product, as well as any declaration of the use of any postharvest treatments.

\section{Transport}

Transportation vehicles should be clean and sanitary. Refrigerated trucks should be used where possible, but at the very least produce should be covered. Refrigerated trucks cannot cool horticultural and at best can only maintain their temperatures if they have been precooled. Therefore, the refrigeration system should be turned on well before loading and precooled products loaded rapidly.

Techniques which can be undertaken to improve organic horticultural produce during storage period

- Stores crop in a darken room. This is especially important for Potatoes, light will stimulate solanine production.

- Utilization of Irradiation technologies for value added organic horticulture produce.

- Do not overload storage rooms.

- Small doses of 2-chloro ethyl cycocel helps in the retard senescence in majority of vegetables during storage.

- Application of different waxes \& oil emulsion have been found effective in increasing the self-life of various fruits during storage period,eg-Apple, Kinnow etc. Wax must not contain any prohibited synthetic substances. Acceptable sources include carnuba or wood -extracted wax. Products that are coated with approved wax must be indicated as such on the shipping container.

- Shading should be given for storage structures to reduce cooling load. 
- Use of postharvest UV light therapy technology for extended preservation of fresh organic fruits and vegetables

- Storing the harvested product at 80 to $90 \%$ relative humidity maintained room for preventing moisture loss.

- Dehydration is the useful techniques to extend the storability of organically grown fruits, vegetables and spices etc.
- Utilization of recyclable and biodegradable packaging material for packaging of organic horticulture produces. eg- biodegradable Styrofoam box, brown paper, Linear low density polyethylene bags, CFB box, Wood fiber box etc.

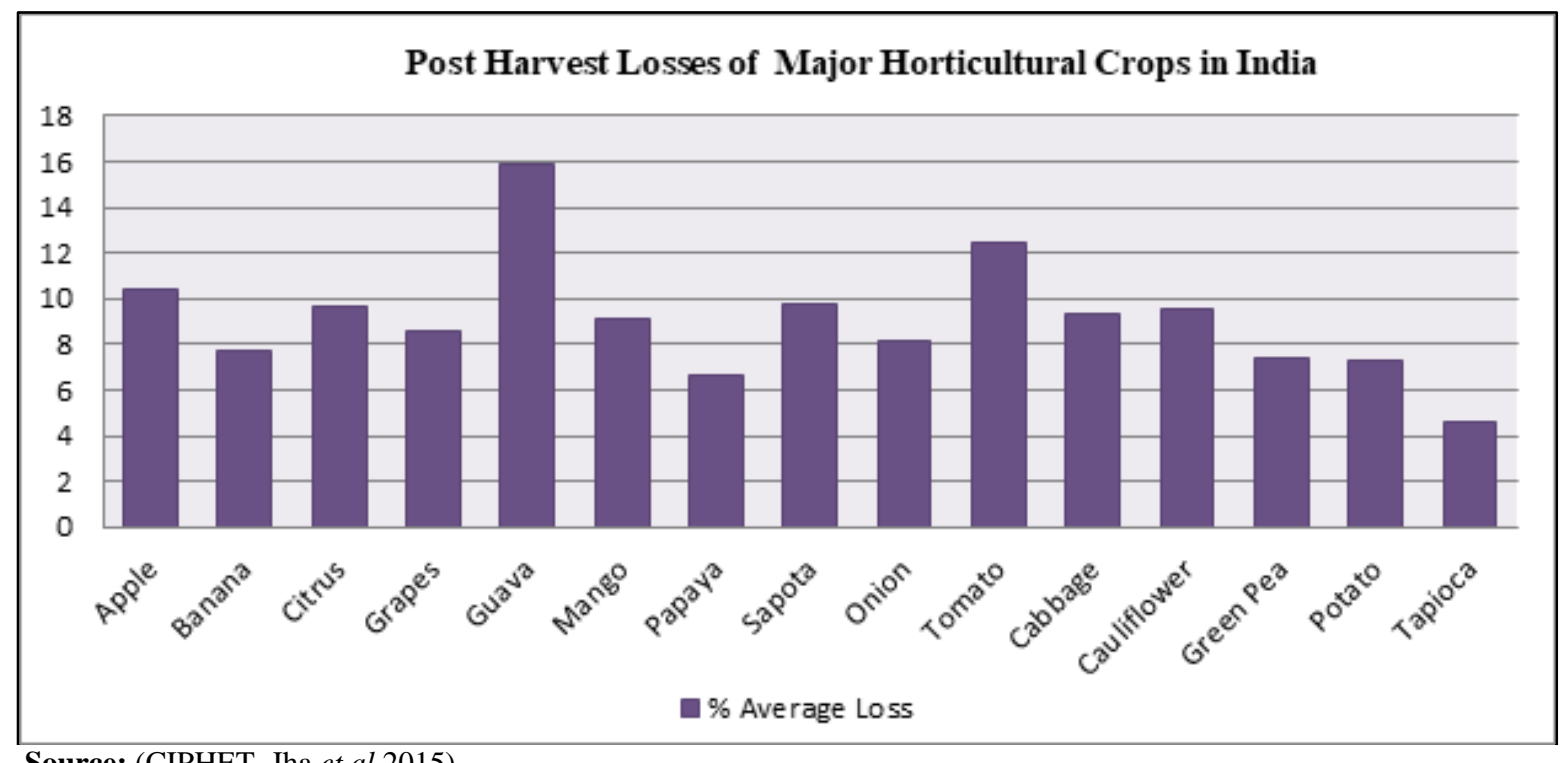

Source: (CIPHET, Jha et al 2015)

Fig 1: Practices for post harvest management of organic produce

\section{Conclusion}

Fruits and vegetables are perishables since they maintain an active metabolism in the postharvest phase. The factors causing early termination of their storage life are relatively high respiration rates and senescence, transpiration, and high susceptibility to fungal infection. Therefore, organic post harvest management practices like Storage, dehydration, value addition and preservation of fruits and vegetables are essential for extending the period of food availability and avoid the problem of contamination of any harmful chemicals along with organically grown fruits and vegetables. However, the technique is purely based upon the scientific principles. Therefore, it is best recommended that proper \& innovative post harvest techniques should be followed for both fresh \& dehydrated organic horticultural produces. This would result in increasing the utility of the commodity \& its life after harvest.

\section{References}

1. Organic Farming Practices: Postharvest Handling, Vegetable Research and Information Center, University of California, 1-9.

2. Food Safety and post harvest handling for organic crops, W. C. Morris, Department of Food science and Technology, Oregon State University, 4-5.

3. Kader A. Increasing food availability by reducing postharvest losses of fresh produce, Acta Horticulturae, 2005; 682(1):2169-2176,

4. Bachmann J, Earles R. Postharvest Handling of Fruits and Vegetables, Appropriate Technology Transfer for Rural Areas, Fayetteville, NC, USA, 2000. 